\title{
Puesta en Valor de la Mampostería Histórica: Casos de Estudio en Mendoza, Argentina
}

\section{Enhancement of historical masonry: case studies in Mendoza, Argentina}

\section{Noemí Maldonado}

Universidad Tecnológica Nacional - Argentina

ngm@frm.utn.edu.ar

\section{Pablo Martín}

Universidad Tecnológica Nacional - Argentina

pablo.martin@frm.utn.edu.ar

\section{Gerardo González del Solar}

Universidad Tecnológica Nacional - Argentina

gerardo.gdelsolar@frm.utn.edu.ar

\section{Ignacio Maldonado}

Universidad Tecnológica Nacional - Argentina

maldonadogeotecnia@yahoo.com.ar

\section{Diego Buss}

Universidad Tecnológica Nacional - Argentina ingdiegobuss@yahoo.com.ar

\section{María Domizio}

Universidad Tecnológica Nacional - Argentina

mcarodomizio@hotmail.com

\section{Resumen}

En América se ha utilizado la mampostería cerámica cocida desde mediados del siglo XVIII la cual forma parte del patrimonio cultural local. La permanencia en el tiempo se debe a su técnica de construcción, calidad de materiales y mantenimiento además del efecto de los terremotos. Se presentan resultados de inspección detallada de cinco construcciones de mampostería cerámica de valor patrimonial con diferentes patologías que requieren 
distintas tecnologías de puesta en valor en la zona de mayor riesgo sísmico de Argentina.

La metodología de estudio utilizada para las propuestas de rehabilitación incluye la modelación por elementos finitos, lo que requiere de parámetros de comportamiento de mampuestos y morteros para comprender las patologías subyacentes obtenidos de ensayos de laboratorio y monitoreo in situ. La puesta en valor debe considerar que no se presente incompatibilidad de materiales aplicando tecnologías locales.

Palabras claves: Patrimonio, Unidades Cerámicas, Morteros, Compatibilidad, Modelación

\begin{abstract}
In America fired ceramic masonry has been used since the mid-18th century and is part of the local cultural heritage. The permanence in time is a product of its construction technology, quality of materials and maintenance, as well as the effect of earthquakes. Detailed inspection results are presented for five heritage-value ceramic masonry constructions with different pathologies that require different enhancement technologies in the area of greatest seismic risk in Argentina.

The study methodology used for the rehabilitation proposals includes finite element modeling, which requires masonry and mortar behavior parameters to understand the underlying pathologies obtained from laboratory tests and in situ monitoring. The enhancement must consider that there is no incompatibility of materials applying local technologies.
\end{abstract}

Keywords: Heritage, Ceramic Units, Mortars, Compatibility, Modeling

\title{
Introducción
}

La mampostería es un material compuesto por unidades naturales o manufacturadas, unidas con mortero, que constituyen el inventario de edificios existentes en el mundo desde la civilización egipcia hasta la actualidad. Las técnicas de construcción más investigadas corresponden a la mampostería de las construcciones griegas y romanas que se han mantenido en pie. En África y Asia la mampostería más antigua estaba hecha de piedra o tierra, en tanto que en América, se utilizó la cerámica cocida a finales del siglo XIX, y que ahora forman parte del patrimonio cultural local.

La preservación de los edificios patrimoniales requiere conocimientos para orientar las estrategias de preservación (Maldonado y Michelini, 1999). Los materiales se degradan con el tiempo cuando están en contacto con el medio ambiente, y este es un proceso natural e inevitable y es necesario determinar la velocidad de deterioro, dato necesario para estimar la vida útil de la construcción en relación con la seguridad y/o funcionalidad (Maldonado et al, 2017).

La mampostería se puede clasificar como portante o no portante. La mampostería portante resiste el propio peso y las cargas de viento o las cargas sísmicas y gravitacionales generadas por los pisos o techos soportados en ella (Klingner, 2010).

La presencia de humedad en los mampuestos, puede provenir del suelo, lluvias o servicios de drenaje defectuosos, causando daños a la mampostería con un impacto mayor en la antigua, y si bien la humedad se puede medir, los resultados no son repetibles. En otros casos, las intervenciones con nuevos materiales han aumentado los problemas de humedad (Maldonado et al, 2017). 


\section{Evaluación metodológica de la construcción histórica}

La metodología se inicia con una evaluación del valor patrimonial de la obra (Figura 1), definiendo las responsabilidades antes de especificar el procedimiento. Todas las actividades implican la interacción de diferentes disciplinas y una gran responsabilidad de la gestión del mantenimiento del patrimonio (Maldonado et al, 2017).

La Figura 2 presenta el procedimiento seguido para la rehabilitación, aplicando los criterios de seguridad establecidos en los criterios de conservación según ICOMOS (ICOMOS, 2003). En esta evaluación, el impacto de la durabilidad de los materiales y la sostenibilidad ambiental con el entorno construido deben incorporarse además de la seguridad en la estructura.

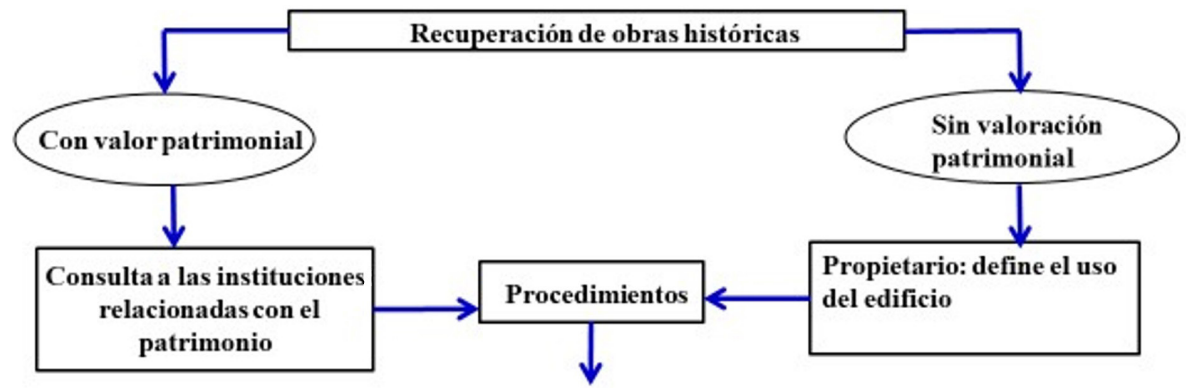

Figura 1: Criterios básicos para la recuperación de obras históricas

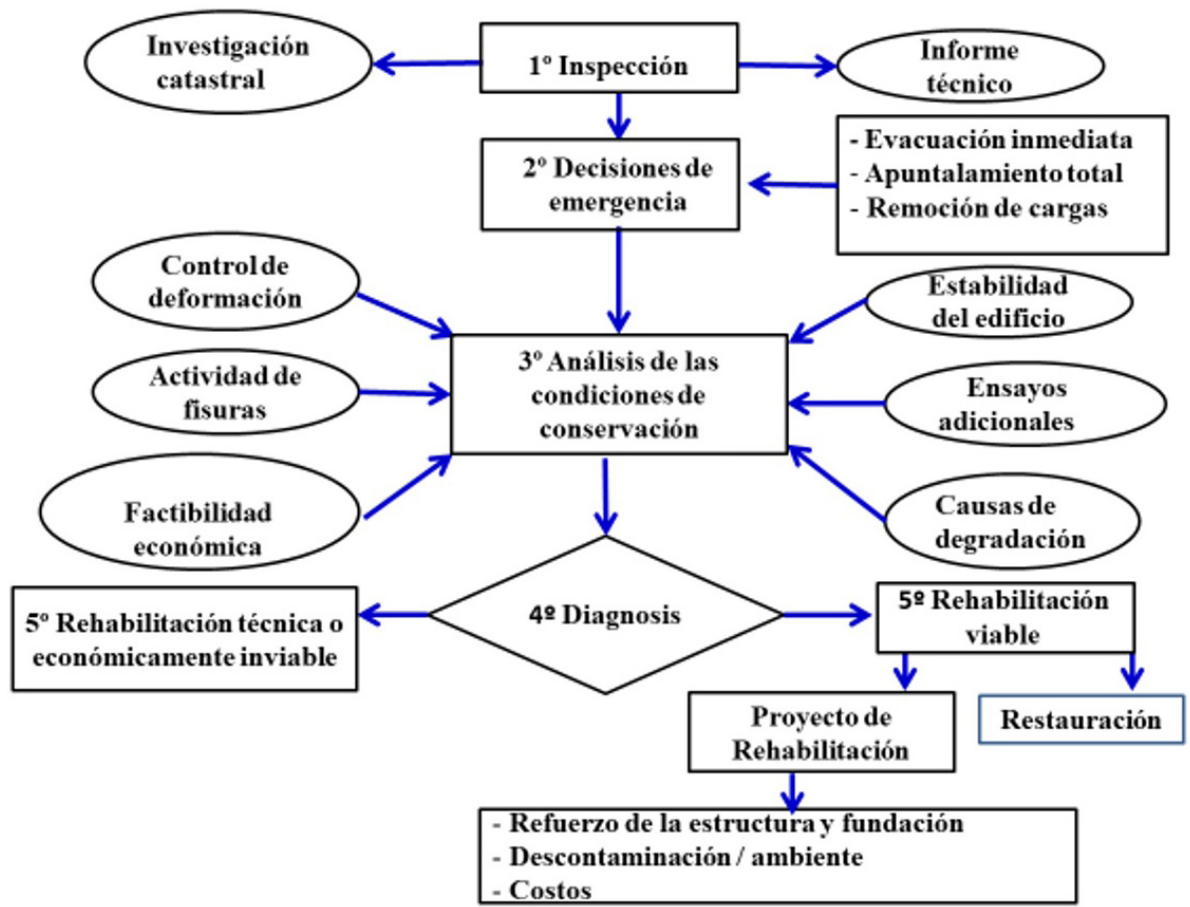

Figura 2: Procedimiento de estudios para la puesta en valor del patrimonio

\section{Mampuesto}

El ladrillo es el material de construcción artificial más antiguo; ejemplares de ladrillos de arcilla secados al sol (adobe) se remontan al año 8000 A. C., en tanto que los ladrillos cocidos 
fueron utilizados ya en 2500 A. C. Los edificios de fines del siglo XIX y principios del siglo XX se caracterizan por el empleo de mampostería de ladrillo cerámico cocido (ISE, 2010). En la transición al uso del acero, aparecen construcciones de hormigón, que emplean perfiles metálicos apoyados en plateas o como vigas y columnas dentro de la mampostería para resistir terremotos (Girini, 2004). Desde 1930 el uso del hormigón armado se ha extendido en el mundo, dejando a los muros de mampostería para estructuras menores, o revestimiento en estructuras de hormigón armado o terminación de fachadas.

Los ladrillos se pueden confeccionar con arcilla, silicato de calcio u hormigón. Las dimensiones del ladrillo pueden orientar sobre su antigüedad, aunque existen variaciones regionales que pueden ser mayores que las relacionadas con la edad (ISE, 2010). La Figura 3 muestra diferentes patrones.

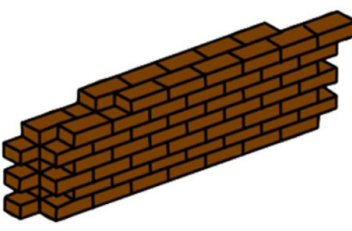

(a)

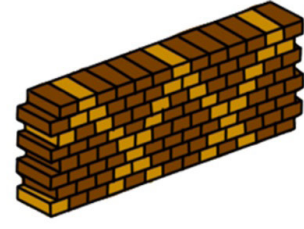

(b)

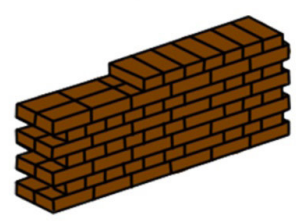

(c)

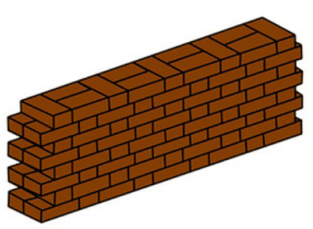

(d)

Figura 3: Disposición de ladrillos sólidos: de soga (a), de cabeza (b), inglés (c) y flamenco (d) (ISE, 2010).

\section{Mortero}

Los morteros en la mampostería histórica se componen de agregados finos, agua y como ligante cales simples o hidráulicas. Se pueden clasificar como morteros simples; morteros hidráulicos y morteros compuestos. Los aglutinantes pueden ser aéreos o hidráulicos, dependiendo del mecanismo de endurecimiento (Válek et al, 2013).

La función del mortero es mantener unidas las unidades de mampostería, compensar sus tolerancias dimensionales y transferir los esfuerzos. Los morteros de cal pura se endurecen debido a la carbonatación del hidróxido de calcio. Se trata de un proceso que puede tomar muchos años, dependiendo de la porosidad de la piedra o ladrillo y del espesor de la pared. Los morteros de cal hidráulica adquieren una mayor resistencia inicial y continúan el proceso de carbonatación a través de los años.

Los morteros a base de cemento pueden ser más fuertes y rígidos, incluso que el mampuesto. Los morteros de cemento y cal tienen resistencias intermedias. Pequeños incrementos de cemento en la mezcla aumentan la resistencia pero reducen su permeabilidad y esto puede provocar daños por heladas en piedra porosa o ladrillo.

Las juntas de mortero pueden erosionarse por la lluvia, agravándose por la descomposición química del ligante, debido a la acidez del agua de lluvia. La resistencia a la intemperie aumenta con la proporción de aglutinante respecto a la arena. Los sulfatos, de cualquier fuente, pueden causar la expansión y la desintegración del mortero. Algunos ladrillos contienen sulfatos que pueden ser lixiviados del mortero.

La resistencia del mortero influye en la resistencia de la mampostería en compresión y tracción y en menor medida a flexión. Los morteros ricos en cemento tienden a contraerse, lo que conduce a una unión débil y al incremento de la permeabilidad de la mampostería. La resistencia a la compresión del mortero en juntas existentes no puede medirse de manera directa, sí se pueden determinar las proporciones de cemento-cal-arena mediante el 
análisis químico de muestras de mortero tomadas de las juntas.

\section{Ensayos de mampostería}

Los ensayos de especímenes extraídos de mampostería histórica son escasos. Pero se han desarrollado investigaciones en réplicas en escala de mampostería sin armar en los Estados Unidos, Italia, Yugoslavia en los últimos 25 años (Klingner, 2010, Tomaževič, 2006) y en Mendoza, Argentina (Maldonado et al., 2011 y González del Solar y Orrego, 2013).

Algunas técnicas de ensayo in situ para caracterizar la mampostería, son los ensayos FlatJack y Pull-Out, los cuales afectan la estructura, y los ensayos no destructivos como ultrasonido, geo-radar, emisión acústica, monitoreo estático, termografía, difracción por rayos $\mathrm{X}$. Los ensayos dinámicos, por otro lado, corresponden a medición de microvibraciones ambientales para monitoreo en el tiempo (Domizio et al., 2015).

\section{Durabilidad y compatibilidad de la mampostería histórica}

Las paredes de mampostería son un sistema abierto que está en contacto con otras estructuras contiguas que forman parte de la dinámica del comportamiento general. Cualquier infiltración se manifiesta en eflorescencias en la superficie formadas por sales como carbonatos, sulfatos, cloruros, nitratos, oxalatos, sodio, potasio, calcio, magnesio y amoníaco, y su presencia varía de acuerdo al tipo de material constitutivo de la mampostería.

Tanto el yeso como las capas de pintura de las paredes son estructuras abiertas con alta porosidad, y una gran superficie expuesta a los agentes de degradación y permeabilidad a los fluidos en contacto con ella tanto líquidos (soluciones de sales diluidas en la pared) como gases (contaminantes atmosféricos y vapor de agua) (Domizio et al., 2019).

Se debe considerar la compatibilidad: Química entre el mortero de reemplazo y el antiguo, Física en relación al proceso de solubilidad de sales y agua de transporte, y Mecánica donde la resistencia del nuevo mortero debe ser similar al de la mampostería histórica.

\section{Comportamiento sísmico de la mampostería histórica}

El comportamiento de la mampostería histórica ha sido satisfactorio a cargas verticales permanentes, pero no cuando las solicitaciones han sido de origen sísmico. La forma en que una estructura se daña durante un terremoto depende de su proximidad a la falla. Resistirán a las exigencias de aceleración y desplazamiento provenientes de los eventos sísmicos aquellas estructuras que cumplan con las nuevas regulaciones, posean un buen diseño estructural y redundancia estática (Maldonado et al., 2017).

El desempeño de diafragmas horizontales en la mampostería histórica es a menudo deficiente debido a la baja transferencia de los esfuerzos a las paredes laterales resistentes. Estos diafragmas suelen ser de madera, débilmente anclada en los muros y estos se ven afectados por deformaciones fuera de su plano, conduciendo al vuelco de la pared y al derrumbe del edificio (Klingner, 2010).

El terremoto de Long Beach (California, 1933) puso en evidencia el mal comportamiento de la mampostería sin armar, derivando a la prohibición de su empleo en edificios escolares. El reglamento UBC de 1943 estableció que la mampostería tenía que cumplir los mismos criterios de diseño del hormigón armado de la época, apareciendo así la mampostería armada. Santiago (Chile) y Ciudad de México (1985), Izmit, Turquía y Quindío, Colombia (1999), Pisco, Perú (2007), L'Aquila, Italia (2009), Lorca, España (2011), Katmandú, Nepal (2015), Manabí, Ecuador (2016) sufrieron terremotos que han demostrado que los edificios de mampostería sin diseño sismorresistente han sufrido daños significativos, especialmente aquellas de 
mampostería de adobe y de piedra (Klingner, 2010, Furukawa et al., 2017, Lanning et al., 2016).

\section{Modelación de la mampostería}

La modelación numérica de la mampostería requiere modelos computacionales que logren captar los diferentes modos de falla, resulten suficientemente precisos y de implementación simple. Existen varias técnicas de modelado. Los micro-modelos consisten en el modelado de las unidades de mampostería y el mortero como elementos continuos, mientras que la interfaz mampostería-mortero se representa por medio de elementos discontinuos. Los macro-modelos son modelos fenomenológicos en los que las unidades de mampostería, mortero e interfaz se representan como un compuesto por medio de un elemento continuo. La técnica a utilizar se basa en el nivel de precisión y simplicidad deseado (Lourenço, 1996).

Los modelos fenomenológicos se centran en la respuesta general de la estructura a un menor costo computacional, a través de un modelo constitutivo cuya respuesta es representativa del comportamiento de los componentes. El modelo constitutivo de Drucker Prager permite representar de una manera simple y sencilla el comportamiento no lineal de la mampostería como un material elastoplástico con dependencia de la compresión actuante, resultando atractivo ya que necesita la definición de pocos parámetros que se pueden determinar a partir de ensayos de compresión diagonal en laboratorio o la aplicación de Flat-Jack in situ. Para obtener los parámetros de modelado de la mampostería, las pruebas de laboratorio se realizan en una escala 1:1 en muestras de diferente espesor (González del Solar et al., 2014). Con los resultados experimentales obtenidos, se formula un modelo de elementos finitos utilizando el software ABAQUS (Hibbit et al., 2011) y cuyos parámetros permiten obtener un comportamiento similar al observado durante las pruebas.

Con el modelo calibrado, se simula la geometría del edificio y el estado de las cargas solicitantes, cuyos resultados se comparan con el daño real. Estos resultados permiten hacer una propuesta de reparación y rehabilitación. La Figura 7 muestra el modelo estructural general y el estado de tensiones de la mampostería de un edificio educativo (Maldonado et al., 2015) con concentración de tensiones en los encuentros de pared y puntos de aplicación de cargas, mientras que el resto de la mampostería se mantiene a un nivel de tensión normal menor a la máxima. La Figura 8 presenta el resultado del modelado para daños en arcos y la Figura 9 muestra el desprendimiento de la fachada principal.

El comportamiento del suelo se analiza mediante el método de elementos finitos, aplicando el criterio de Mohr-Coulomb (Maldonado et al., 2015), esto es necesario ya que las intervenciones a nivel de fundación solo son aplicables cuando está comprobada la falta de capacidad portante del suelo. La Figura 10 corresponde a la condición del suelo de un edificio escolar patrimonial (Maldonado et al., 2011) y la Figura 11 muestra la concentración de tensión en las paredes de la nave central como resultado del asentamiento diferencial entre el sector central y los laterales debido a la presencia de jardines (Maldonado et al., 2015). 


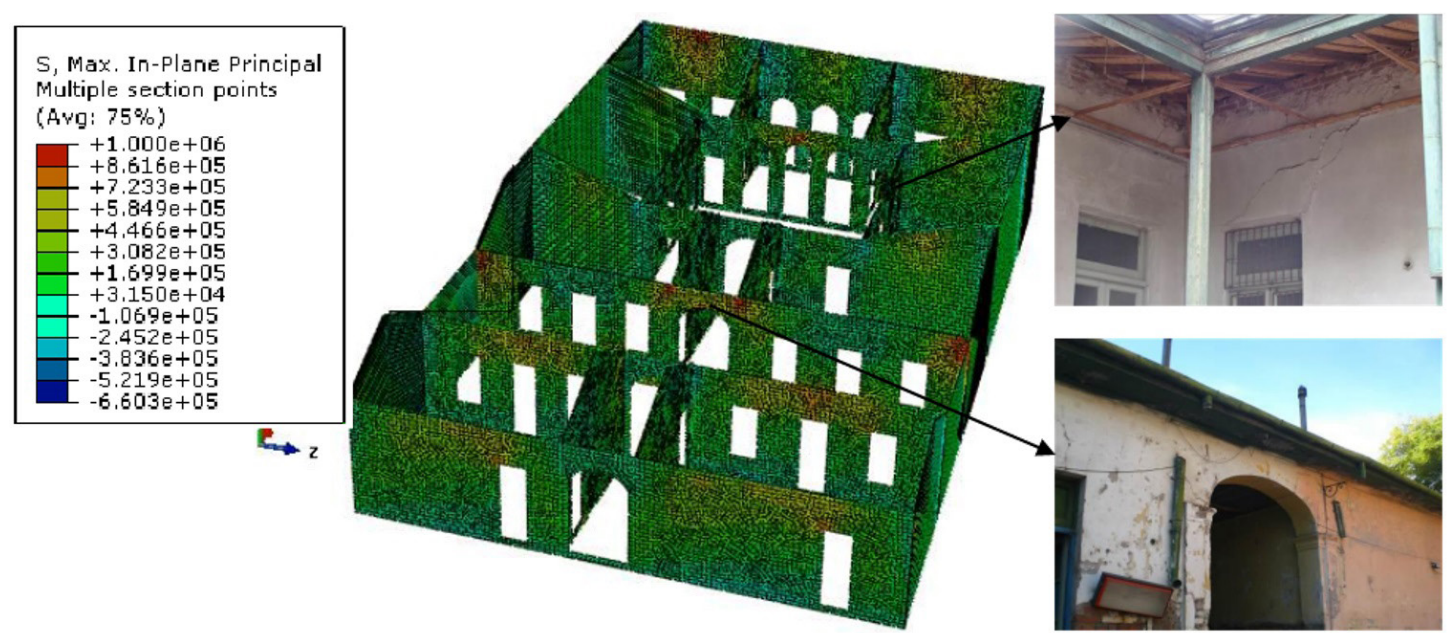

Figura 7: Comparación del estado de tensión del modelo y estado de daño al edificio (Maldonado et al., 2015)

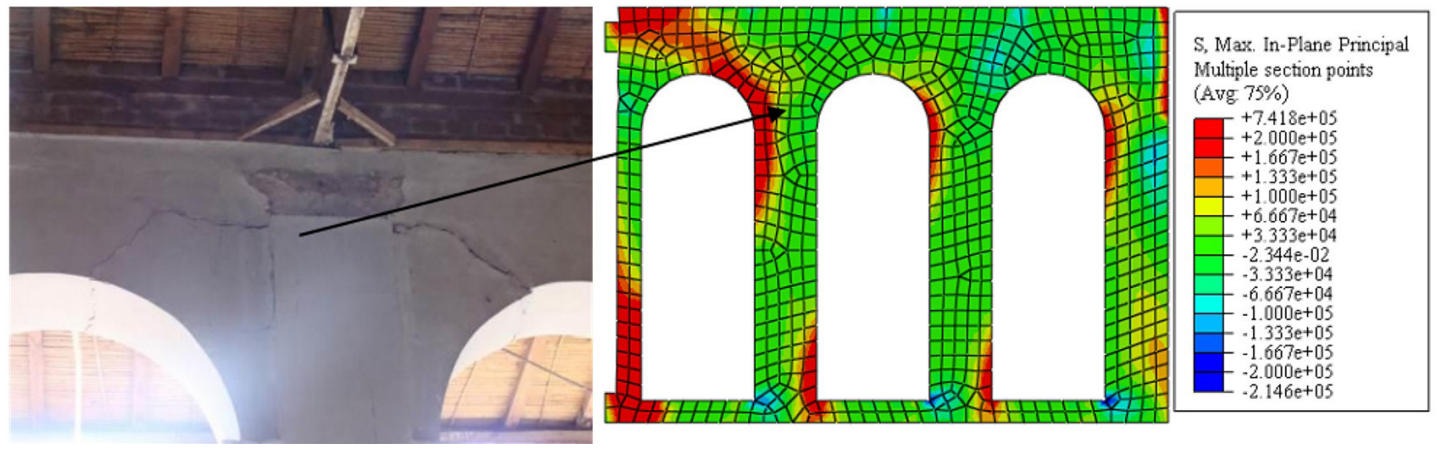

Figura 8: Comparación entre el modelado del estado de tensión y el estado de daño del edificio (Maldonado et al., 2015)

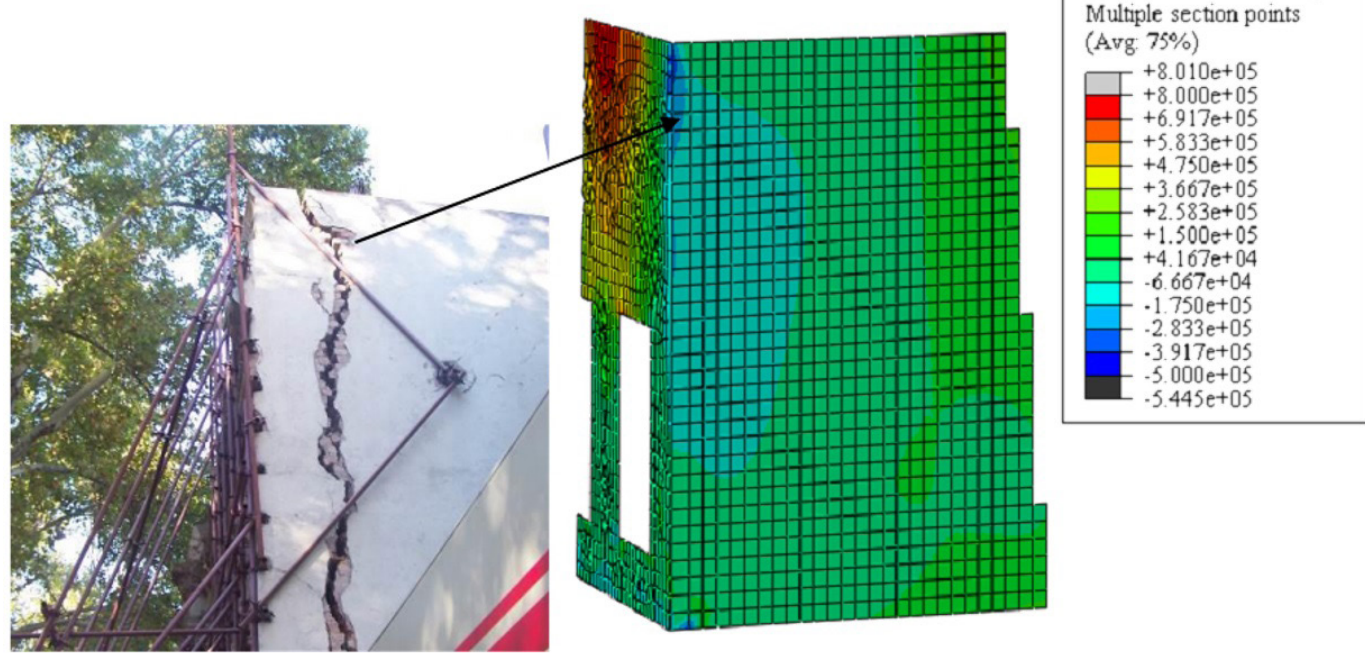

Figura 9: Simulación de daños en la fachada debido a una cimentación ineficiente (Maldonado et al., 2015) 


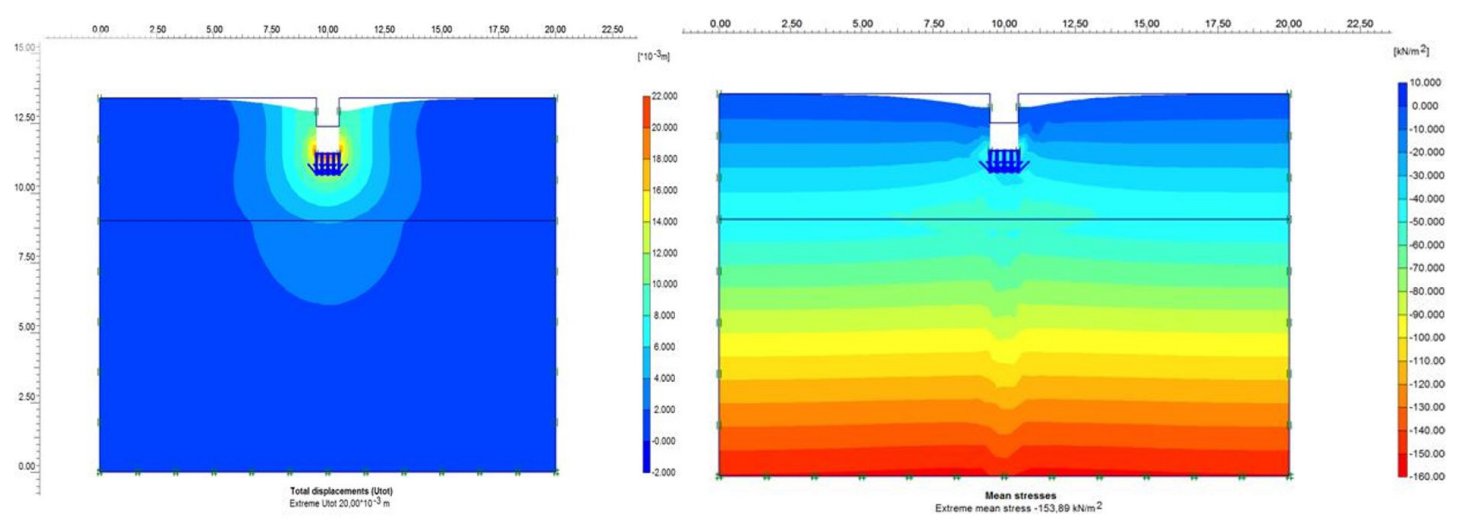

Figura 10: Estado de deformación bajo cimiento de mampostería (izq.) y estado tensional (der.) en edificio educacional (Maldonado et al., 2011)

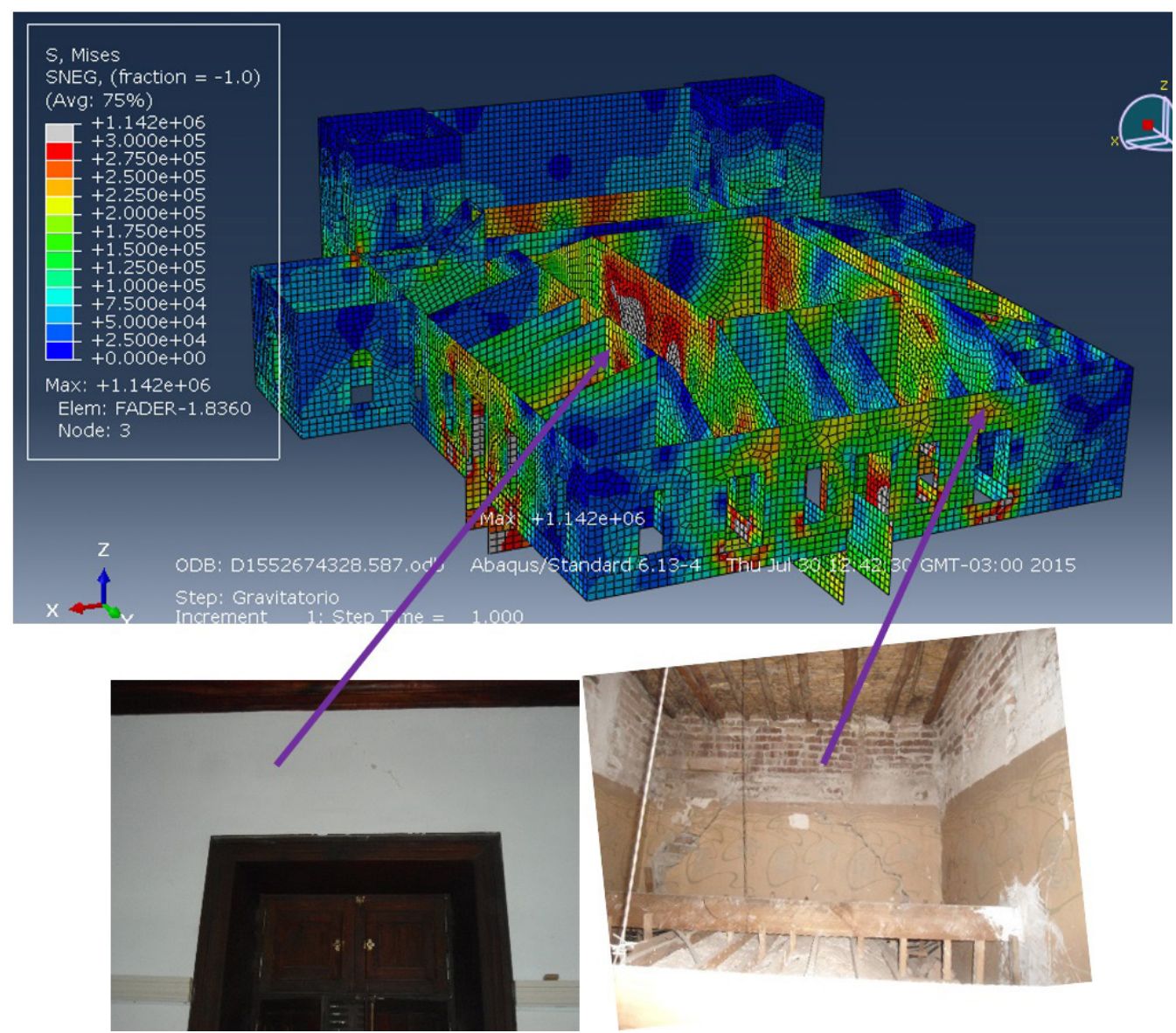

Figura 11: Daños debidos a asentamientos diferenciales de distintos sectores (Maldonado et al., 2015)

\section{Reparación, rehabilitación y refuerzo de la mampostería histórica}

Un gran número de estructuras históricas no cumplen con el nivel de seguridad exigido por la reglamentación vigente. Además por el paso del tiempo desde su construcción, el grado de seguridad ha disminuido debido al uso y a las condiciones ambientales. Para elevar 
en estos edificios históricos el grado de seguridad, es necesario adaptar su estructura, sin perder el valor histórico por la intervención, y esto exige nuevos enfoques.

La rehabilitación estructural de los edificios históricos podría hacerse ocultando esos nuevos elementos estructurales o exponiéndolos, esta decisión debe ser analizada y consensuada por los profesionales de la preservación participantes del proyecto. En una zona de elevado riesgo sísmico es difícil seguir estrictamente los principios de las diferentes cartas de restauración (Venecia, Atenas, etc.) y la tarea es un desafío de la ingeniería estructural (Maldonado et al., 2015).

"Reparación" hace referencia a una intervención posterior al evento sísmico que ocasionó el daño. Esta reparación no aumenta la resistencia sísmica de una estructura más allá de su estado anterior al terremoto. Por otro lado, los términos "refuerzo", "refuerzo sismorresistente" o "actualización sísmica" comprende intervenciones técnicas en el sistema estructural de un edificio con el fin de mejorar su capacidad sísmica mediante el aumento de la resistencia y la ductilidad. Según la terminología propuesta, el refuerzo de un edificio antes de un terremoto se llama "rehabilitación", mientras que el fortalecimiento posterior al evento se llama "retrofit o puesta en valor"(Tomaževič, 2006).

Las técnicas de refuerzo dependen de la respuesta del edificio al terremoto. Las intervenciones pueden ser:

- Mejorar la respuesta global del edificio (en caso de comportamiento de tipo caja de construcción y una respuesta en el plano principal, Figura 12)

- Mecanismos locales (en caso de una respuesta fuera del plano principal, Figura 13 izq.)

- Sobre estructuras de bloques (donde deben prevenirse los mecanismos cinemáticos; obeliscos, torres y también arcos y bóvedas, Figura 13 der.)
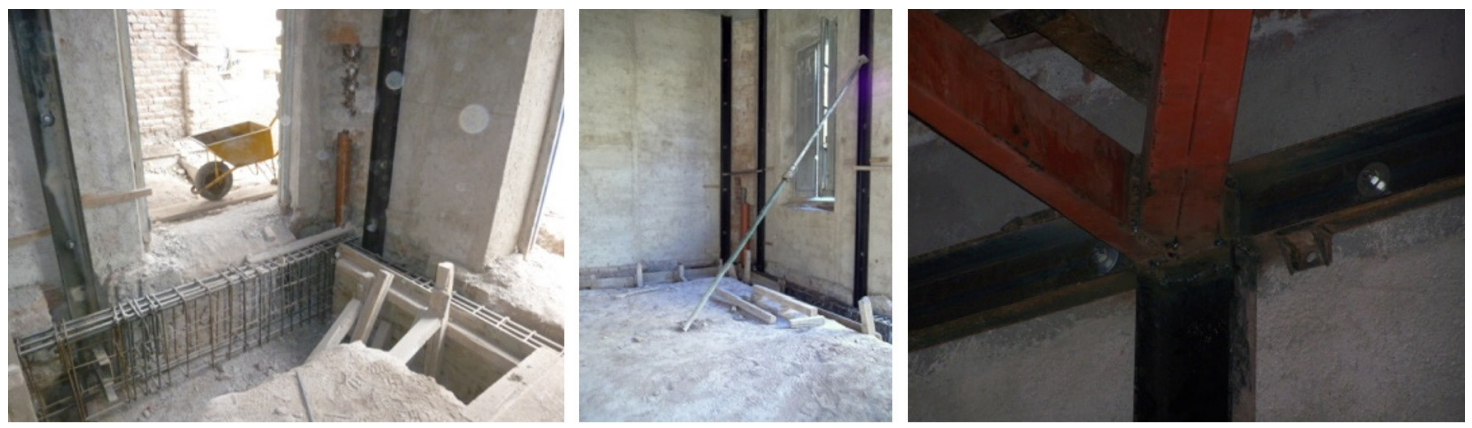

Figura 12: Refuerzo de cimientos y estructuras metálicas reversibles en columnas y vigas, Escuela Mitre, 2012 

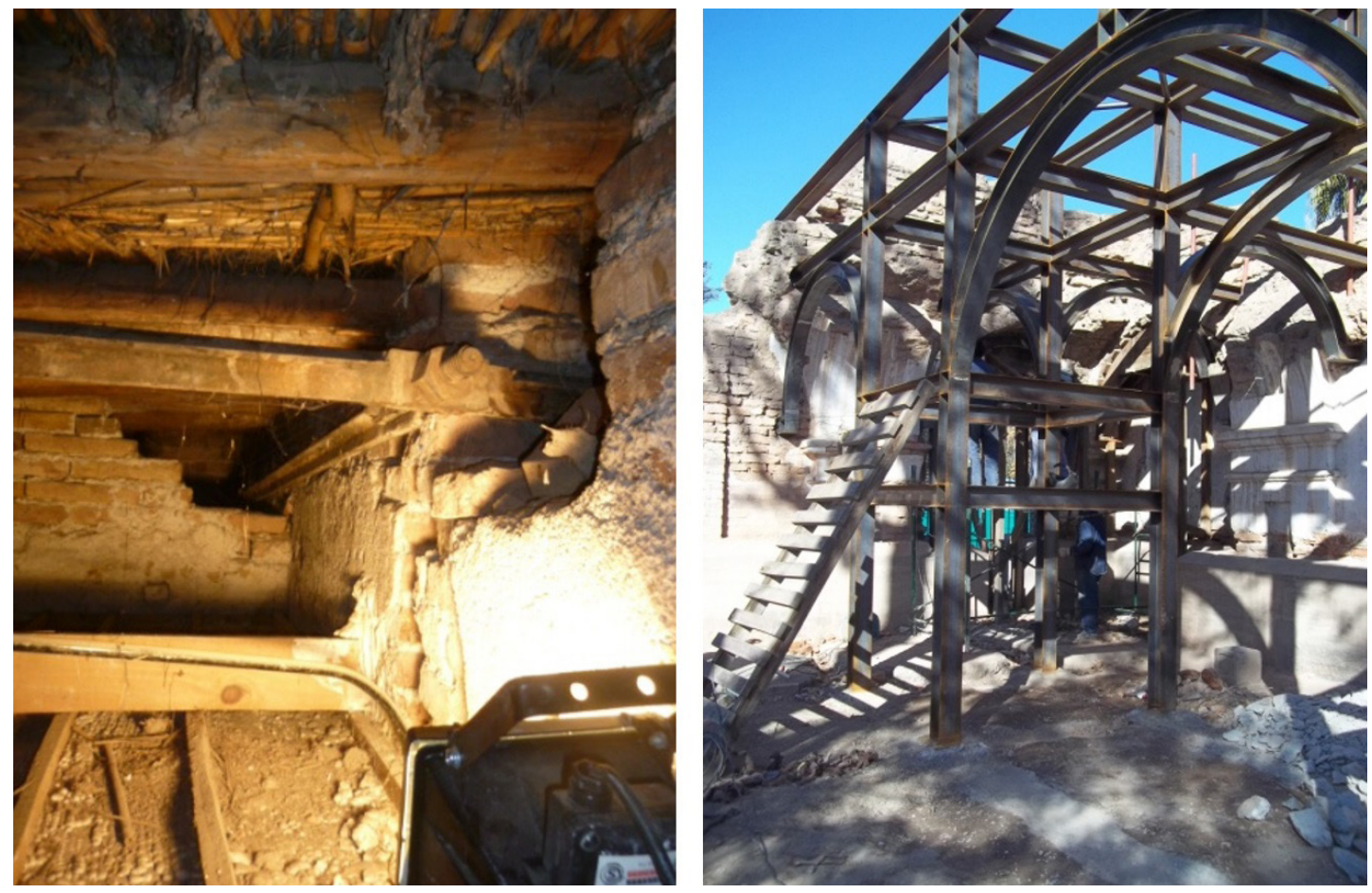

Figura 13: Tensores bidireccionales para el refuerzo de paredes de mampostería histórica, Casa de Fader, 2013 (izq). Estructura de apoyo de bloques de mampostería, Ruinas de San Francisco, 2011(der).

En el proyecto PERPETUATE, Gostič et al., (2012) han evaluado tanto las técnicas de intervención tradicionales como las innovadoras. La elección de la técnica de rehabilitación depende del estado de la mampostería, la disponibilidad de mano de obra local y los requisitos de seguridad (ICOMOS, 2003).

La eficacia de una rehabilitación puede evaluarse mediante técnicas de identificación de sistemas, midiendo las propiedades dinámicas de la estructura antes, durante y después del refuerzo estructural. Las vibraciones de baja amplitud provienen de diferentes fuentes, entre ellas, el tráfico vehicular, los micro-tremores, el viento, etc. En el caso de la mampostería el parámetro utilizado para medir la eficiencia de la rehabilitación estructural es el período de las paredes medidas en la parte superior de las mismas (Domizio et al., 2015).

\section{Casos de estudio}

La Tabla 1 presenta las características catastrales de los edificios históricos de mampostería estudiados en Mendoza, Argentina de 1999 a 2020 (CeReDeTeC, 1996, 2000, 2006, 2013, 2014).

La Tabla 2 muestra los datos obtenidos en la evaluación del estado de los edificios históricos de mampostería antes de la puesta en valor.

La Tabla 3 presenta los criterios del modelado del suelo y de la mampostería para los diferentes edificios estudiados. 


\begin{tabular}{|c|c|c|c|c|c|}
\hline Evaluado & $\begin{array}{c}\text { Ruinas de San } \\
\text { Francisco. } \\
\text { Capital }\end{array}$ & $\begin{array}{c}\text { Escuela Mitre. } \\
\text { Capital }\end{array}$ & $\begin{array}{c}\text { Edificio de } \\
\text { Turismo. } \\
\text { Capital }\end{array}$ & $\begin{array}{c}\text { Chalet Giol. } \\
\text { Maipú }\end{array}$ & $\begin{array}{l}\text { Casa de Fader. } \\
\text { Luján de Cuyo }\end{array}$ \\
\hline $\begin{array}{c}\text { Fecha de } \\
\text { construcción }\end{array}$ & Siglo XVIII & $\begin{array}{l}\text { finales del siglo } \\
\text { XIX -1906 }\end{array}$ & 1910 & 1910 & $\begin{array}{l}\text { Casa } 1892 \\
\text { 1905-6 Pinturas }\end{array}$ \\
\hline $\begin{array}{l}\text { Fecha de } \\
\text { estudio }\end{array}$ & 1996 & 2000 y 2010 & 2006 y 2020 & $2012-13$ y 2020 & $2013-14$ \\
\hline $\begin{array}{l}\text { Responsable } \\
\text { patrimonial }\end{array}$ & $\begin{array}{l}\text { DNA** } \\
\text { Municipalidad de } \\
\text { Mendoza }\end{array}$ & DP-GM* & DP-GM* & $\begin{array}{l}\text { DNA** } \\
\text { Municipalidad } \\
\text { de Maipú }\end{array}$ & $\begin{array}{l}\text { DP-GM* } \\
\text { DNA** }\end{array}$ \\
\hline Uso previsto & $\begin{array}{l}\text { Museo al aire } \\
\text { libre }\end{array}$ & $\begin{array}{l}\text { Museo } \\
\text { educativo }\end{array}$ & $\begin{array}{l}\text { Centro de } \\
\text { información } \\
\text { turística }\end{array}$ & $\begin{array}{l}\text { Museo de la } \\
\text { vendimia }\end{array}$ & $\begin{array}{l}\text { Museo de } \\
\text { Bellas Artes }\end{array}$ \\
\hline $\begin{array}{l}\text { Antecedentes } \\
\text { arqueológicos } \\
\text { e históricos }\end{array}$ & $\begin{array}{l}\text { Estudios } \\
\text { históricos y } \\
\text { arqueológicos }\end{array}$ & $\begin{array}{l}\text { Pocos estudios } \\
\text { históricos y } \\
\text { arqueológicos }\end{array}$ & $\begin{array}{l}\text { Pocos estudios } \\
\text { históricos y } \\
\text { arqueológicos }\end{array}$ & $\begin{array}{l}\text { Estudios } \\
\text { históricos. } \\
\text { Sin estudios } \\
\text { arqueológicos }\end{array}$ & $\begin{array}{l}\text { Pocos estudios } \\
\text { históricos. } \\
\text { Sin estudios } \\
\text { arqueológicos }\end{array}$ \\
\hline
\end{tabular}

Referencias: *DP-GM: Dirección de Patrimonio Gobierno de Mendoza **DNA: Dirección Nacional de Arquitectura

Tabla 1: Datos identificatorios de los edificios estudiados

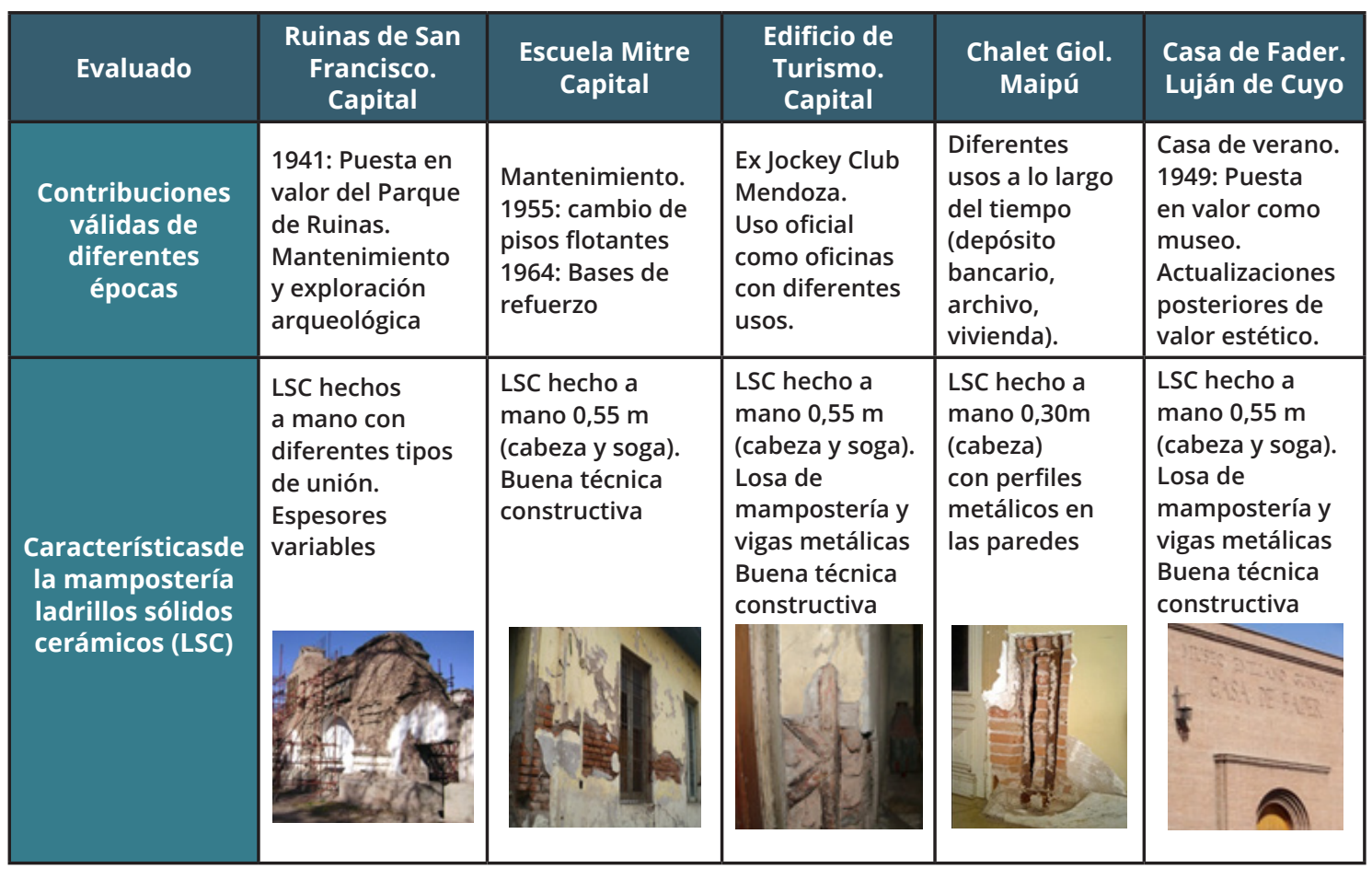




\begin{tabular}{|c|c|c|c|c|c|}
\hline Evaluado & $\begin{array}{c}\text { Ruinas de San } \\
\text { Francisco. } \\
\text { Capital }\end{array}$ & $\begin{array}{c}\text { Escuela Mitre } \\
\text { Capital }\end{array}$ & $\begin{array}{l}\text { Edificio de } \\
\text { Turismo. } \\
\text { Capital }\end{array}$ & $\begin{array}{l}\text { Chalet Giol. } \\
\text { Maipú }\end{array}$ & $\begin{array}{l}\text { Casa de Fader. } \\
\text { Luján de Cuyo }\end{array}$ \\
\hline $\begin{array}{c}\text { Principales } \\
\text { problemas } \\
\text { detectados, } \\
\text { daños y } \\
\text { durabilidad }\end{array}$ & $\begin{array}{l}\text { 1861: } \\
\text { Destrucción por } \\
\text { terremoto } \\
\text { Deterioro por } \\
\text { intemperie } \\
\text { (capilaridad). } \\
\text { Agrietamiento en } \\
\text { áreas críticas. } \\
\text { Imposición de } \\
\text { vegetación. }\end{array}$ & $\begin{array}{l}\text { 1985: terremoto } \\
\text { fisuró tímpanos. } \\
\text { 2006: terremoto } \\
\text { separó la } \\
\text { fachada. } \\
\text { Falta de } \\
\text { encadenados. } \\
\text { Asentamiento en } \\
\text { arcos. } \\
\text { Problemas en el } \\
\text { drenaje de agua y } \\
\text { alcantarillado. } \\
\text { Eflorescencia y } \\
\text { sales solubles. }\end{array}$ & $\begin{array}{l}\text { Corrosión de } \\
\text { cables y perfiles } \\
\text { Expansión de } \\
\text { morteros. } \\
\text { Problemas en el } \\
\text { drenaje de agua } \\
\text { y alcantarillado. } \\
\text { Eflorescencia y } \\
\text { sales solubles }\end{array}$ & $\begin{array}{l}\text { Corrosión } \\
\text { de cables y } \\
\text { perfiles } \\
\text { Expansión de } \\
\text { morteros. } \\
\text { Problemas } \\
\text { en el drenaje } \\
\text { de agua y } \\
\text { alcantarillado. } \\
\text { Eflorescencia y } \\
\text { sales solubles }\end{array}$ & $\begin{array}{l}\text { Agrietamiento } \\
\text { de mampostería, } \\
\text { mezclas de } \\
\text { materiales, falta } \\
\text { de capacidad } \\
\text { portante del } \\
\text { suelo. Aportes } \\
\text { de humedad de } \\
\text { jardines y agua } \\
\text { de lluvias. } \\
\text { Eflorescencia y } \\
\text { sales solubles }\end{array}$ \\
\hline $\begin{array}{l}\text { Riesgo sísmico } \\
\text { regional }\end{array}$ & $\begin{array}{l}\text { Alto (suelo } \\
\text { aluvial) }\end{array}$ & $\begin{array}{l}\text { Alto (suelo } \\
\text { aluvial) }\end{array}$ & $\begin{array}{l}\text { Alto (suelo } \\
\text { aluvial) }\end{array}$ & $\begin{array}{l}\text { Alto (suelo } \\
\text { aluvial) }\end{array}$ & $\begin{array}{l}\text { Alto (suelo } \\
\text { aluvial) }\end{array}$ \\
\hline $\begin{array}{l}\text { Causas de daños } \\
\text { estructurales }\end{array}$ & $\begin{array}{l}\text { Terremoto de } \\
\text { Mendoza de } 1861 \\
\text { y posteriores }\end{array}$ & $\begin{array}{l}\text { Terremoto de } \\
\text { Mendoza de } 1985\end{array}$ & $\begin{array}{l}\text { Falta de } \\
\text { mantenimiento }\end{array}$ & $\begin{array}{l}\text { Falta de } \\
\text { mantenimiento }\end{array}$ & $\begin{array}{l}\text { Varios } \\
\text { temblores. } \\
\text { Intervenciones. } \\
\text { Falta de } \\
\text { mantenimiento. }\end{array}$ \\
\hline
\end{tabular}

Tabla 2: Características de intervenciones anteriores y mampostería, patologías existentes y riesgo sísmico

\begin{tabular}{|c|c|c|c|c|c|}
\hline Evaluado & $\begin{array}{c}\text { Ruinas de San } \\
\text { Francisco. } \\
\text { Capital }\end{array}$ & $\begin{array}{c}\text { Escuela Mitre. } \\
\text { Capital }\end{array}$ & $\begin{array}{l}\text { Edificio de } \\
\text { Turismo. } \\
\text { Capital }\end{array}$ & $\begin{array}{l}\text { Chalet Giol. } \\
\text { Maipú }\end{array}$ & $\begin{array}{l}\text { Casa de Fader. } \\
\text { Luján de Cuyo }\end{array}$ \\
\hline $\begin{array}{l}\text { Modelado } \\
\text { del suelo }\end{array}$ & $\begin{array}{l}\text { Triángulo } 15 \\
\text { nodos Mohr- } \\
\text { Coulomb. Plaxis } \\
\text { Bv }\end{array}$ & $\begin{array}{l}\text { Triángulo } 15 \\
\text { nodos Mohr- } \\
\text { Coulomb. Plaxis } \\
\text { Bv }\end{array}$ & Teoría elástica & Teoría elástica & $\begin{array}{l}\text { Teoría elástica } \\
\text { Interacción con } \\
\text { Abaqus }\end{array}$ \\
\hline $\begin{array}{l}\text { Modelado } \\
\text { de la } \\
\text { estructura }\end{array}$ & $\begin{array}{l}\text { Elástico } \\
\text { Teoría de Midlin } \\
\text { Plaxis Bv }\end{array}$ & $\begin{array}{l}8 \text { nodos } \\
\text { Isoparamétricos } \\
\text { no lineales } \\
\text { Abaqus } \\
\text { Cubierta: } \\
\text { SAP2000 lineal }\end{array}$ & $\begin{array}{l}\text { Incorporación } \\
\text { de pórticos } \\
\text { de hormigón } \\
\text { armado. } \\
\text { Retrofit de la } \\
\text { mampostería }\end{array}$ & $\begin{array}{l}\text { Placas } \\
\text { lineales de } \\
\text { mampostería } \\
\text { Cubierta: } \\
\text { SAP2000 lineal }\end{array}$ & $\begin{array}{l}\text { Modelo no } \\
\text { lineal Drucker } \\
\text { Prager } \\
\text { mampostería } \\
\text { Abaqus } \\
\text { Cubierta: } \\
\text { SAP2000 lineal }\end{array}$ \\
\hline $\begin{array}{l}\text { Seguridad } \\
\text { estimada }\end{array}$ & $\begin{array}{l}\text { Soporta } \\
\text { terremoto IV MM }\end{array}$ & $\begin{array}{l}>80 \% \text { de la } \\
\text { original }\end{array}$ & $\begin{array}{l}>80 \% \text { de la } \\
\text { original }\end{array}$ & $\begin{array}{l}>80 \% \text { de la } \\
\text { original }\end{array}$ & $\begin{array}{l}>80 \% \text { de la } \\
\text { original }\end{array}$ \\
\hline $\begin{array}{c}\text { Tipo de } \\
\text { intervención } \\
\text { propuesta }\end{array}$ & $\begin{array}{l}\text { Reversible } \\
\text { (apuntalamiento } \\
\text { temporal) hasta } \\
\text { el proyecto de } \\
\text { consolidación } \\
\text { final }\end{array}$ & $\begin{array}{l}\text { Reversible } \\
\text { (refuerzo } \\
\text { metálico exterior } \\
\text { encadenado) } \\
\text { Irreversible en } \\
\text { fundaciones }\end{array}$ & $\begin{array}{l}\text { Irreversible } \\
\text { (eliminación } \\
\text { de perfiles } \\
\text { corroídos) } \\
\text { Verificación de } \\
\text { fundación según } \\
\text { proyecto }\end{array}$ & $\begin{array}{l}\text { Irreversible } \\
\text { (eliminación } \\
\text { de perfiles } \\
\text { corroídos) } \\
\text { Sin } \\
\text { intervención en } \\
\text { fundación. }\end{array}$ & $\begin{array}{l}\text { Reversible } \\
\text { (refuerzo } \\
\text { metálico } \\
\text { exterior } \\
\text { encadenado). } \\
\text { Irreversible en } \\
\text { fundaciones. }\end{array}$ \\
\hline $\begin{array}{l}\text { Estado } \\
\text { actual }\end{array}$ & Ejecutado & Ejecutado & Propuesto & Propuesto & Ejecutado \\
\hline
\end{tabular}

Tabla 3: Modelización y tipo de intervención 


\section{Conclusiones}

El estudio de rehabilitación de mampostería involucra un equipo de especialistas de historiadores, arquitectos, ingenieros estructurales, geotécnicos, técnicos, químicos, etc. Es decir, no puede considerarse sólo como un problema estructural.

La sismicidad del lugar y el abandono de los edificios antiguos han provocado el derrumbe de la mayoría de los edificios antiguos, lo que ha llevado a la pérdida de valores culturales que han sido parte de la historia local. Por lo tanto, la rehabilitación de edificios antiguos debe considerarse una política de estado, con el fin de preservar los pocos edificios que quedan.

Se destaca que en la región con terremotos de fallamiento de origen cercano los edificios históricos que han permanecido en pie se componen de ladrillos sólidos cerámicos, sólo muy pocos de adobe y piedra han logrado sobrevivir debido a la alta demanda de ductilidad de los terremotos.

El modelado por MEF aplicando modelos constitutivos no lineales, proporciona una herramienta eficaz para la simulación y verificación de edificios históricos de mampostería, por lo que es necesario investigar la formulación de modelos constituyentes eficientes para la mampostería de mayor espesor.

El monitoreo a través de la medición de vibraciones ambientales ha sido una herramienta útil para evaluar el nivel de recuperación de la construcción, permitiendo en el futuro evaluar el estado de conservación de la misma. 


\section{Referencias}

CeReDeTeC. (1996). Informe técnico de las Ruinas de San Francisco. Ciudad. Mendoza. Mendoza: UTN,1-29.

CeReDeTeC. (2000). Informe técnico 2-2000. Ex Escuela Mitre. Ciudad. Mendoza. Mendoza: UTN,1-88.

CeReDeTeC. (2006). Informe técnico 4-2006. Edificio Sede de la Subsecretaría de Turismo, Ciudad, Mendoza. Mendoza: UTN,1-24.

CeReDeTeC. (2013). Informe técnico 2-2013. Chalet Juan Giol, Maipú. Mendoza. Mendoza: UTN, $1-43$.

CeReDeTeC. (2014). Informe técnico 1-2014. Museo Emiliano Guiñazú, Casa de Fader, Luján de Cuyo, Mendoza. Mendoza: UTN, 1-111.

Domizio. C., Calderón, F., Maldonado, N. (2015). Riesgos al sur. Diversidad de riesgos de desastres en Argentina. Buenos Aires: Imago Mundi, 177-196.

Domizio, M., Maldonado, N., Arena, A., Fernández Luco, L. (2019). ”Importance of environmental monitoring, after the rehabilitation of heritage masonry buildings in seismic zone: case study". Structural Analysis of Historical Constructions. An Interdisciplinary Approach RILEM Bookseries 18, 1, 2395-2403.

Furukawa, A., Kiyono, J., Parajuli, R., Parajuli, H., Toki, K. (2017). "Evaluation of Damage to a Historic Masonry Building in Nepal through Comparison of Dynamic Characteristics before and after the 2015 Gorkha Earthquake”. Frontiers in Built Environment, 3, 62.

Girini, L. (2004). "Arquitectura, Industria y Progreso. Las bodegas vitivinícolas de Mendoza en el Centenario”, Tesis (Dr. en Arquitectura), Universidad de Mendoza, Argentina.

González del Solar, G., Orrego, J. (2013). "Estudio del comportamiento de muros de mampostería simple de gran espesor solicitados biaxialmente”, Tesis de Grado, Universidad Tecnológica Nacional, Mendoza.

González del Solar, G., Martín, P., Calderón, F., Maldonado, N., Maldonado, I. (2014). "Importancia de la modelación numérica en la puesta en valor de estructuras patrimoniales de mampostería en zona sísmica”. Revista ALCONPAT , 3, 215-231.

Gostič', S., Uranjek, M., Simonič, M., Štampfl, A. (2012). "DELIVERABLE D34 Results of experimental tests on strengthening techniques and guidelines for the design.” PERformance-based aPproach to Earthquake proTection of cUlturAl heriTage in European and mediterranean countries. Disponible en < http://www.PERPETUATE.eu/d34/>.

Hibbitt, H., Karlsson, B., Sorensen, P. (2011). Abaqus Theory Manual. Version 5.8. Estados Unidos: Dassault Systèmes Simulia Corp.

ICOMOS Charter 2003. (2003) "Principles for the analysis, conservation and structural restoration of architectural heritage”. International Council on monuments and sites. Disponible en: <https://www.icomos.org/victoriafalls2003/iscarsah_guidelines.doc>

Klingner, R. (2010). Masonry Structural Design. New York: McGraw-Hill, 133-179.

Lanning, F., Haro, A., Liu, M., Monzón, A., Monzón-Despang, H., Schultz, A., Tola, A. (2016). 
EERI Earthquake Reconnaissance Team Report: M7.8 Muisne, Ecuador Earthquake on April 16. California: EERI. 1-92. Disponible en: <http://www.eeri.org $>$

Lourenço, P. (1996). “Computational Strategies for Masonry Structures”, Thesis (Ph. D), Delft University of Technology, The Netherlands.

Maldonado, N., Martín, P., Maldonado, I. (2011). "Seismic Mitigation of a Historic Masonry Building”. The Open Construction and Building Technology Journal. 5, I-M3, 61-70.

Maldonado, N., Martín, P., Maldonado, I., Calderón, F., González del Solar, G., Domizio, M. (2015). "Estudios para la puesta en valor de edificio patrimonial con pinturas murales en zona sísmica: un caso de estudio”. Memorias XIII Congresso Latino-Americano de Patologia da Construção CONPAT 2015, Lisboa, Portugal, 8 al 10 de Setiembre, 3.4., 7205.

Maldonado, N., Martín, P., Maldonado, I., Domizio, M., González del Solar, G., Calderón, F. (2017). "Behaviour and Durability of Ceramic Heritage Masonry in Near Source Fault Zone". Proceedings 16th World Conference on Earthquake, 16WCEE, Santiago de Chile, 9 al 13 Enero, $1,3371$.

Maldonado, N., y Michelini, R. (1999). “Técnicas aplicadas para la restauración de construcciones antiguas de mampostería en zona de elevado riesgo sísmico”, Memorias V Congreso Iberoamericano de Patología de las Construcciones y VII Congreso de Control de Calidad CONPAT99, Montevideo, Uruguay, 18 al 21 de Octubre, 1581-1586

The Institution of Structural Engineers (ISE). (2010). Appraisal of existing structures. London: ISE, 44-45.

Tomaževič, M. (2006). Earthquake-Resistant Design of Masonry Buildings. London: Imperial College Press, 203-252.

Válek, J., Hughes, J., Groot, C. (2012). Historic Mortars. Characterisation, Assessment and Repair. RILEM: Springer, 1-444. 